from the point of view of the price of the raw materials if the success of the hardening process had not made the softer, unsaturated oils also available.

Few, if any, developments of recent years have been more remarkable and more truly chemical than that connected with the so-called hardening of fats-the realisation on an industrial scale of that very simple exercise in organic chemistry, the reduction of an unsaturated double bond by means of hydrogen. How simple it seems, and yet the leading expert on the chemistry of fats said not many years ago that it could not be done. Even Sabatier, the discoverer of the efficacy of metallic catalysts in the hydrogenation of vapours, expressly stated that his process failed with liquids. Normann's first patent for the hydrogenation of liquid fats was based, as all experimental work must be, on work done in the laboratory; there he was successful, and though his patent was crudely drawn-and who would have done better? - the great idea was there. Yet the successful. application on the large scale took many years of arduous work and much capital expenditure. The German firm, Leprince and Sievke, who first bought Normann's process, made little of it, and parted with it to Joseph Crosfield and Sons, of Warrington, in whose hands it has been brought to its present success. The innumerable patents on the subject are little more than variations of the original idea of Normann-acts of piracy, for the most part, arising out of the present unsatisfactory condition of the patent laws. Yet a perusal of the most recent book on hydrogenation leaves the reader almost ignorant of the existence of the Warrington firm.

Not so many years ago glycerine was an almost worthless bye-product of the soap industry, and the spent lyes from the soap-pan were originally concentrated for the sake of the salt they contained. To-day the lyes are purified with the utmost care, and the glycerine is concentrated, distilled, and refined until the article sold is of quite remarkable purity considering its low price. The practical problem-one of chemical engineering-is to evaporate water from the dilute lyes until a crude glycerine is obtained at the cheapest possible cost. The contrast between the original shallow open pans heated by a fire and the elaborate multiple-effect vacuum evaporators with salting arrangements which are used to-day is a striking one. It is typical of the advances made in chemical engineering, a branch of the chemical profession which is as important industrially as that of the laboratory worker.

The stearine candle industry has lost ground owing to the powerful competition of gas and electricity in towns and the development in the use of cheaper paraffin, but it is still of importance both in England and abroad. The old empirical methods of preparing and blending the raw materials have given way to modern processes based on the knowledge of the chemical properties of the substances concerned.

Equally important as chemical achievements must rank the great developments in the processes of refining oils so as to render vegetable oils in particular available for edible purposes. This branch of the subject was described at some length in Nature of April 8 (vol. xcv., p. 145).

Space forbids more than brief reference to the industries concerned with lubricating oils or with boiled oils for making varnishes and paints. The latter are almost wholly concerned with linseed oil, and their problems are connected with oxidising and changing the oils.

The outlook for the future in these industries in Britain may be faced with confidence. The tendency to aggregate the production in large factories enables a competent staff of chemists to be employed, and avoids the pitfalls consequent in the practice of rule-of-thumb methods in small concerns. Competition ensures the constant striving to invent and develop new and cheaper processes, and at the same time safeguards the public interests by providing them with a cheap article, the low price at which fat and oil products are retailed at the present day being one of the most remarkable testimonies to the development of the industry.

\section{THE DYE FAMINE IN AMERICA AND THE PROPOSED REMEDY.}

$R E C E N T$ issues of the Scientific American 1 (November 6 and 13 ) contain articles by Prof. T. H. Norton, of the Bureau of Foreign and Domestic Commerce, Washington, dealing with the prevailing shortage of dyes in the United States. For some months after the outbreak of the European war, American importers were able to secure an almost normal supply of synthetic dyes, but during the last seven months, owing to the embargo on the shipment of German dyes to neutral countries, only 50 tons of such colouring matters have reached America, together with small amounts of dyes of Swiss origin.

Before the war, American dye factories employed not more than 400 workmen and produced annually 3000 tons of dyes, these colours being prepared chiefly from intermediate coal-tar products made in Germany.

After a systematic examination of the dye problem by the Department of Commerce, the Secretary of Commerce, on September 30, outlined the policy of the present administration in regard to the protection to be afforded to American chemical enterprise against unfair attacks by foreign rivals. In the meantime, prompt and resolute decisions had been made by the industrialists, and considerable investments were made in new plant, two new companies having an authorised capital of 400,oool. and 3,ooo,oool. respectively. The output of American coal-tar colours has been doubled and will soon be trebled, while the production of benzene and toluene has increased fivefold. Owing to the extensive manufacture of explosives, it is difficult at present to secure large quantities of these hydrocarbons for colour production. But twelve firms have nevertheless embarked on the manufacture of aniline, the Edison Company now turn- 
ing out three tons of this intermediate product daily. A remarkable and novel development has arisen in this branch of the colour industry. The firms engaged in dyeing aniline black are setting up small aniline plants costing $300 l$. to $400 l$. each, capable, under the supervision of one operative, of producing daily soo $\mathrm{lb}$. of aniline from benzene.

At present the seven companies engaged on finished coal-tar dyes are restricting drastically the number of colours produced, and are concentrating on increased output. Two works are specialising in an ample supply of chlorodinitrobenzene, from which two other well-equipped factories are manufacturing sulphide black on a huge scale. Synthetic indigo is receiving the attention of four powerful chemical companies.

Although the existing equipment for natural dyes installed in six large American works has proved to be a national asset of great value, yet the total supply of dyes is still far short of customary requirements, and the American public is urged to meet the abnormal situation in a spirit of generous compromise. The existing shortage will soon disappear, inasmuch as the United States possess all the enterprise, inventive talent, and technical ability requisite for the development of an American dye industry. As regards the practical experience of industrial colour syntheses, it is suggested that the services of a corps of expert Swiss colour chemists would be of untold value in accelerating the evolution of the new industry. This scheme has already been adopted successfully in Russia, where a group of dye consumers have formed a company, including as a constituent member a leading Basle firm, which supplies a technical staff to the enterprise.

One reason for the former dominance of German colour chemistry was the unity and solidarity of the various firms engaged in this industry, so that when one was menaced by any foreign competitor they all acted in unison. In America the field has been entered by many separated interests imperfectly acquainted with the complexity of the colour problem. A plea for a higher degree of unity is put forward in order to avoid overlapping and duplication of effort. It has been proposed to establish Government factories for the production of coal-tar intermediates, these factories to be available for manufacturing explosives in case of war. A national bureau of standards for dyestuffs would afford considerable protection to the growing industry, and a similar result would be attained by organising the consumers of dyes.

In view of these developments, it appears certain that in a few years America will be practically self-contained as regards dyes. It is not at all probable that the vast industrial organisations by this time established will content themselves with catering only for the American market, especially as the United States possess sufficient of the needed raw materials to supply the whole world's dye industry. British dye producers must expect to face, not only furtive attempts to recover trade by German competitors, but also a direct frontal attack on their home, colonial, and foreign markets by dye-wares of American origin. The only way of meeting this invasion will be by a combination, first of British manufacturers among themselves, and secondly a co-operative union of the British group with similar groups representing the other nations of the Quadruple Entente. The pooling of our resources for war will need to be followed by a partnership in original ideas, technical organisation, and natural resources in regard to the chemical industries of the allied nations.

G. T. M.

\section{OPTICAL INVESTIGATION OF ETHER- DRIFT.}

O $\mathrm{F}$ all the attempts made to detect a possible influence of the motion of the medium on optical phenomena, the only one giving a positive result, was the celebrated experiment of Fizeau, in which interference was produced between two beams of light which passed along tubes containing running water, the one beam going with the current and the other beam against it. When the direction of the current was reversed the bands were displaced, and the displacement could be explained on the assumption that the ether in the tubes drifted with the current with a velocity $v\left(\mathbf{I}-\mathbf{I} / \mu^{2}\right)$, where $v$ is the velocity of the water. Fizeau obtained a I 4 per cent. agreement between theory and experiment, which was regarded as satisfactory in view of the difficulty of the subject. The experiment was afterwards repeated by Michelson and Morley with more refined means, and they obtained a difference of less than $I$ per cent. with a calculated probable error of about 5 per cent.

In 1895 , however, in his "Versuch einer Theorie der electrischen und optischen Erscheinungen in bewegten Körpern," Lorentz gave a new expression for the velocity of the ether drift, namely :-

$$
v\left(\mathrm{I}-\frac{\mathrm{x}}{\mu^{2}}-\frac{\lambda}{\mu} \frac{d \mu}{d \lambda}\right)
$$

This expression is also obtained on the theory of relativity. In the case of water it is quite 3 per cent. larger than Fresnel's value. We have just received two papers reprinted from the Proceedings of the Amsterdam Academy, which describe an elaborate experimental investigation made by Prof. Zeeman at Amsterdam to decide between the two expressions. (Vol. xvii., pp. 445-45I, I9r4, and vol. xviii., pp. 398-408, I9I5.)

The interference fringes were produced by Michelson's method. The length of the tubes was 6 metres and the maximum velocity of the water 5.5 metres per second. As the expression to be tested varies only slightly with the wave-length, the light of an arc lamp could be used as source after it passed through a monochromator. The fringes were recorded photographically; the cross-wires in the focal plane of the telescope came out on the negative, and the displacement of the fringes relative to the cross-wires was No. 2407, VOL. 96] 